among the Indian immigrants, and only very few among the lascar crews; two cases of the latter I shall refer to presently. At the same time I had several cases among Chinese passengers who fed on far better diet than the Indian coolie; but these Chinese in two vessels had only come a short voyage from Mauritius, and had possibly contracted the disease before embarking.

\section{Metal Poisoning.}

This has been suggested as a cause of beri-beri; some captains of vessels are firmly convinced this is so. On more than one occasion I have been asked to see some tins of meat opened to give an opinion on them. Possibly the theory is due to cases of metal poisoning having been mistaken for beri-beri. It is not at all unlikely that rations may become contaminated with metals, especially now that tinned foods are so largely used; and the question of metal water tanks, too, must be remembered.

\section{Toxic Theory.}

The facts, as I have observed them, do not support the ventilation or diet theory, but rather favour the theory that the disease is caused by the absorption of a toxin formed by an organism outside the body.

I have given a good deal of careful consideration to the cases I have met with, and it seemed to me possible that the organism or origin of the disease, whatever it may be, might exist in the water and mud of tropical rivers, not necessarily in the drinking water, and that infection in the case of shipping was taken on board with the wet wood cargoes or the wet sand ballast, anchors, and cables, so that when the crew for any reason were rendered susceptible to the poison, either on account of being run down from fever, hard work, sudden change of climate, or from sickness of any kind, the disease manifested its presence.

First, I noticed that the small barques which were infected generally discharged their light cargoes at tropical or subtropical ports, and then took in wet sand ballast, and, of course, at the same time drinking water.

In the case of ships which had sailed from Rangoon I found that the timber taken in had been soaking for some considerable time in water, and the fact that the crews of wood vessels seemed most liable to the disease, combined with other factors, led me to suspect the wet-sand ballast and wet logs as the cause of the trouble. It is after a vessel leaves Rangoon that the disease most usually makes its appearance; possibly Rangoon is more highly infected than East African ports. Vessels coming to Table Bay for assistance usually stated that the first case occurred ten to twenty days out from port, but at the same time I was told that, as a rule, it was not until the ships crossed the line and encountered cold weather that the disease made its appearance.

I account for the various periods at which the disease breaks out after leaving port in this way: In the case of vessels in which the disease breaks out only ten days after sailing the crew may have been run down at starting by malaria, or possibly by the drunken debauch which sometimes precedes departure from port, and they may on these accounts be more susceptible to the action of the poison.

On the other hand, cases in which the disease does not appear for a month or more after sailing may be due to the fact that the crew started in good health, and time was required for the virulence of the poison to increase before making itself felt, or the sailors may become more susceptible after crossing the line, owing to change of temperature, excessive work through bad weather, or the want of fresh food.

The captain of one of these vessels informed me that beriberi was endemic among the population at Rangoon who lived on the sea coast, that is, among lighthouse keepers, fishing populations, etc., whereas people living a little inland were free. This statement would also point to infection being obtained in some way from the water. However, I observe on referring to Scheube's map that the whole of Burmah is there marked as affected. The case of the two lascars before referred to as suffering from the disease on a steamer from Bristol, one of whom died, the other man having been treated for supposed Bright's disease at Bristol, and having evidently been sick for some time, may appear to be an exception to my previous statement. But it is significant that the boat came from an Indian port to Bristol, and further, she had an old-fashioned forecastle, so that the cable came through the hawse-pipe into the men's quarters, bringing up a quantity of mud and water when the anchor was raised, which in itself might suffice to produce the toxin, as the mud and water would spread over the deck of the whole forecastle, and, in the case of an old vessel, get between the seams of the deck planks; it would certainly not be removed by even careful scrubbing, and the deck of the forecastle is not over-carefully scrubbed.

Outside the marine population, as far as South Africa is concerned, cases of the disease chiefly occur among the Chinese. The peculiar liability of the Chinese race to beriberi might be accounted for by the fact that the victims have come from infected marshy districts in China, and, having suffered from the disease previously, are liable to relapse or are more susceptible to the toxin. I have seen a case of the disease in Johannesburg, and a medical man there told me that he had had about a dozen other cases among Chinamen. Now, though Johannesiourg is highly situated, it has a swampy portion, and the Chinese seem to congregate round the swampy area, which is waterlogged, and which may be infected with the disease. I do not suggest that the limited evidence $I$ have cited is conclusive, but it seems to me perfectly consistent with Sir Patrick's Manson's theory as far as it goes.

I had no opportunity of studying the pathology or treatment of the disease, but one thing I noticed was that some of these wood barques of which $I$ have been speaking were actually supplied with several gross of capsules containing iron and extract of bone marrow for the treatment of beriberi, which shows that the captains of these vessels expect in the course of the voyage to be attacked with the disease.

Further, from the account of a Norwegian captain, some vessels are more prone to infection than others, one vessel of which I obtained a history had cases of beri-beri on four voyages out of five. Unfortunately, my notes made at the time are missing, and I cannot give full details, but it seems to point to the vessel having at some time received more infection than usual, so that the virulence of the toxin was continually being augmented; thus, when an opportunity offered, the poison made itself manifest by an outbreak of the disease.

\section{NOTES ON CASES OF SPIRILLUM FEVER IN UGANDA.}

\author{
AOBREY D. P. HODGES, and PHILIP H. ROSS, \\ M.D.Lond \\ Uganda \\ M.R.C.S., L.R.C.P., D.P.H. \\ Protectorate. \\ Uganda.
}

ON October 23rd, 1903, in examining a blood film from an Indian, spirilla were found scattered eparsely through the slide, one occurring in about fifteen to twenty fields. They stained blue with Leishman's stain, were sharply pointed at both ends, varied in length between $36 \mu$ and $42 \mu$, and were about $4 \mu$ in diameter.

As up to this time no case of spirillum fever had been recognized as such or recorded in Uganda, a special interest attached to this discovery. Moreover, the patient being an Indian, the question arose whether he could have brought the infection from his own country, butas he had been over a year resident in Uganda this was not deemed likely. He was first seen on the morning of October 23rd, having been taken ill only the night before. There was no history of a previous attack. His condition when seen was as follows:

He was a small, poorly-nourished man of about $30 ;$ his temperature was ro3. $4^{\circ}$; he was prostrate, anxious, vomiting continually a greenish vomit, and complaining much of pain in the epigastrium and the small of the back. He also had a rather severe headache and pains in the limbs. There was slight tenderness over the liver and spleen and some slight enlargement of the latter. The urine was febrile, and contained nothing abnormal. In the afternoon his temperature was still over ro $3^{\circ}$, and the next morning it was normal, having fallen in the small hours apparently by crisis. In blood flims taken the next morning no spirilla could be found. He complained then of nothing but weakness, and in anuther day was at work again.

On November 1 ith - the nineteenth day-the patient had a relapse almost exactly resembling in symptoms and duration the first attack, and spirilla were found in both fresh and stained specimens of blond. $\Lambda$ few drops of blood from the finger-tip were drawn off with the usual precautions into I per cent. solution of potassium citrate, and the mixture injected subcutaneously into a monkey (Cercopithecus).

The following results occurred :

On November 16 th, three and a half days after inoculation, the monkey's morning temperature was $105.6^{\circ}$, and numerous spirilla were 
found in the blood. The temperature remained high during the three following days, spirilla being easily found each day. On November 20 th the temperature fell by crisis, and remained normal till November 24 th, no spirilla being found in the blood till the mornings of November 25 th and 26 th, when the monkey's temperature was over $106^{\circ}$ and spirilla were very numerous. On November 26 th the temperature again fell by crisis and spirilla again disappeared. On November 28 th the temperature rose to $105.2^{\circ}$, but no spirilla could be found. From this date till December $15^{\text {th }}$ the temperature remained normal and blood examinations were negative, but on the latter date the morning temperature was $105.8^{\circ}$ and the evening temperature r06.2 ${ }^{\circ}$, and spirilla were present in large numbers.

There had thus been an interval of eighteen days during which no spirilla could be found in the blood even by prolonged search, and this interval was of just the same length as the apyrexial interval in the patient from whom the monkey was inoculated. No further relapse occurred in the monkey.

Our attention having been drawn by this case to the spirillum, films were thenceforward examined from every case of pyrexia coming under observation. Over 60 cases have been examined, and in 12, including the first case, spirilla have been found. Of the other cases most were found to have malaria, and in a few nothing at all was discovered.

The 12 cases of spirillum fever have included natives of Uganda, of the East Coast, Sudanese, 2 Indians, and 8 European. In 7 of the cases the disease was probably contracted in Entebbe, and the other 5 patients had recently come from the southern parts of the Protectorate. A most marked feature of the cases has been that very few spirilla may be found in a specimen taken from a patient suffering from a clinically severe attack. In only 2 of the cases have spirilla been at all numerous, while in I case nearly two hours' search ended in finding two spirilla.

In the case of the European, with each of us looking at a specimen, one of us found two or three spirilla, the other finding none, and this was the case of a man with a severe first attack which was afterwards followed by two relapses a intervals of seven days. Moreover, in neither relapse were spirilla found atall. In the one relapse hitherto seen in a native, which was severe though of short duration, very few spirilla were found. In the one fatal case spirilla disappeared from the peripheral blood twenty-four hours before death, the temperature being still high and the patient in a "typhoid"condition. Relapses have been noted in three cases only at present; in two cases they were absent, and in the rest no information has yet been obtained.

It would seem, therefore, that spirilla may be even more scarce in relapses than in the original attack, and it is possible that some of the other pyrexial cases examined, in which nothing was found, may have been spirillum fever, especially as experience has shown that the spirillum does not always stain well with Leishman, which is our usual stain for malaria. In some cases the organism stains satisfactorily, in others, with exactly the same technique, it stains very faintly, and may readily be missed when looked for with a one-sixth objective and high ocular, and may be barely visible even with the oilimmersion. With aniline gentian violet or dilute carbolfuchsin the organism stains well and can easily be picked up with a one-sixth objective and even a 2 ocular.

In practice we now take two films and stain one with aniline gentian violet or carbol-fuchsin. and the other with a Leishman, and afterwards, if we find it necessary, wipe off the oil with xylol from the Leishman film and, without further fixing, restain with one of the other stains.

Although in several cases the organism was seen in fresh specimens, this mode of examination was not found to be reliable, as only a momentary glimpse of a single organism was occasionally obtained, even where they were known to be present. There appears to be little or no movement of the blood corpuscles in a scanty infection-nothing comparable to that caused by a trypanosome or a filaria.

The disease would certainly seem to be widespread in Uganda, and the fact that hitherto it had not been recognized is probably due to the absence till lately of facilities for microscopic examination, as well as to the difficulty in many cases of finding the organism in the blood and to its bad staining properties with some stains. In addition, unless in severe cases, it would be clinically indistinguishable from the ordinary attacks of malaria in natives, for which disease they are seldom admitted to hospital, while the occurrence of relapses in their case would not readily be known without special inquiry, as is shown by the difficulty encountered in many of the cases, even after the diagnosis has been made, of getting authentic information as to a relapse having occurred. Further, it is found that, in the blood of a native with malaria who cannot possibly have had quinine, sometimes only one infected corpuscle may be found in 2 large blood film, while a great number of the large mononuclear leucocytes may contain pigment even in cases wherethere are no clinical signs of malaria. So that, whereas formerly if after twenty or thirty minutes' search pigmented leucocytes were found, but no malarial parasites, the case was regarded as almost certainly malarial, the experience of further cases has resulted in no case, in which malaria? parasites are not seen, being now put down as malarial unless, after prolonged examination of large blood films, no spirilla are found but only pigmented leucocytes.

The importance of correct diagnosis is well shown by the case of the European. This patient had never had malaria, but for several weeks before his attack had been camping in a very malarial district. Clinically his disease might equally well have been malaria, and, prolonged examination of his blood showing nothing-he had been taking quinine-the most probable diagnosis with his history would have been malaria, had not the last corner of one of the slides shown that it was spirillum fever. This patient, therefore, is now free from fear of malarial recurrences, and can go his way, taking no quinine, or only prophylactic doses, with unshaken faith in the precautions he has hitherto been taking against malaria.

It seems probable that the organism itself is the spirochaeteobermeieri, butlack of time and material have prevented further experiments on other animals to see if they are susceptible, or whether, as with the spirochaete obermeieri the monkey is the only animal in which the disease can be reproduced. With the spirochaete obermeiera relapses in the monkey are described as rare or non-existent, but in this case the monkey had two well-marked relapses.

Clinically, and without the knowledge of the occurrence of one or more relapses, there would be great difficulty, as has been mentioned above, in distinguishing the spirillum fever which we have seen from malaria. Hitherto no specia) symptoms have been seen which might not equally well occur in the latter disease, but some general points of difference may be noted :

r. The occurrence of vomiting, which is infrequent in malaria in natives, seems more common among them in spirilluw fever.

2. The complaints of pain, either in the head, back, or limbs, are more noticeable in spirillum fever.

. The subsequent prostration is generally more marked, relatively to the duration of the attack, than in malaria.

4. The pyrexia is less subject to remissions and tends to subside by crisis.

Of these the last is the most important and generally useful.

Addendum.-Since the above notes were written spirilla have been found in one of the cases with regard to which we have stated that nothing whatever was discovered in the blood and that, in our opinion, some of them might have been spirillum. fever.

This case, a European, was first seen on the morning of February 4 th, having returned from a journey in Buddu (South of Uganda) the day before. He had already had two days' "fever," his temperature was ro $4^{\circ}$, his respiration hurried, he was vomiting frequently and complained much of headache. The necessaries for taking blood films were not at hand, and he was given quinine hypodermically on the chance that his disease was malaria. When seen in the early evening. his temperature was normal, and blood films were not then taken as he had apparently reacted to quinine, and parasites would probably be absent from the peripheral blood. He remained well till February $x_{5}$ th, when blood films were taken at the height of fever and most carefully examined. Nothing was found however, neither spirilla, malarial parasites, nor pigmented leucocytes. The examination was the more carefully made because his general clinical condition during fever strikingly resembled that of the other European whose case we report. The temperature fell in a few hour to normal, and similar attacks recurred on February 20 th and 23 rd and on March rst. On the first two of these dates examination of films taken during the pyrexia again gave negative results, and on the $23 \mathrm{rd}$ the intervals having been very irregular and the last one very short, it was thought that the case must after all be malarial. He had been taking ro grains daily of quinine bisulph. in tabloids, and, as these seemed to be ineffectual, he was given 15 grains of the hydrochloride in cachets every morning. On March rst, being much troubled with tinnitus, he did not take his quinine, and as at 9 a.m. he felt cold, he took his temperature and found it to be $100^{\circ}$. When seen at ro a.m. his temperature was $100.7^{\circ}$, and blood films were at once taken. In these two or three spirilla were found in each large fllm, and about the same number in a film taken shortly after, when his temperature had risen to $104^{\circ}$

The scarcity of spirilla in the peripheral blood is rendered the more striking by the fact that the case was really a severe one, for, although the pyrexial periods were of short duration, 
the prostration aiter each relapse was marked, and the patient lost weight between February 4th and March ist, to the extent of I st. Io lb.

It will be seen that the difficulties of clinical diagnosis, to which we have drawn attention, were increased by the irregular intervals between the relapses, the shortness of the pyrexial periods, and, at one time, by the apparent reaction to quinine. The case appears, therefore, to emphasize what we have already said, not only as to the difficulty but as to the importance of diagnosis by the microscope.

[NOTE. - To this paper was attached a number of carefullykept clinical charts, the publication of which is, however, unnecessary, since the usual cause of the pyrexia is sufficiently explained in the text.]

\section{MEMORANDA! \\ MEDICAL, SURGICAL, OBSTETRICAL, THERA- PeUtical, Pathological, Fto.}

THE OPENING OF PERITONSILLAR ABSCESSES.

Trat the most suitable position for reaching the pus in a peritonsillar abscess is not generally recognized was forcibly brought to my mind, about eighteen months ago, when on taking my seat for the viva voce examination in surgery held for an M.D. for general practitioners I was asked by a leading London surgeon, "Where would you open a quinsy ?" and upon my replying, "Through the soft palate above the anterior pillar of the fauces," the expression on the examiner's face, and his exclamation of "Where?" was not at all calculated to give one the idea that he was going to have a pleasant ten minutes at the surgery table. A little further explanation on my part, however, made all go smoothly. The knowledge of the "site of election" I obtained from a short article by Mr. R. Lake in the Medical Annual for 1898. I have always, however, used a vertical incision, and provided one keeps well outside the vertical line of Dr. StClair Thomson, the operation is a very successful one-one might say, one of the most successful minor operations, from the patient's point of view especially, which falls to the lot of the general practitioner. Another very important point is also brought out in this article-namely, that the haemorrhage so much dreaded is doubtless often due to timid procrastination, allowing the arterial wall to become so softened that it ruptures at the moment external pressure is reduced.

$$
\text { hlresford, Hants. } \quad \text { F. W. JOLLYE, M.D., F.R.C.S.E. }
$$

\section{ENTERECTOMY AT TWELVE HOURS OLD:} RECOVERY.

cAN find no record of enterectomy at such an early age and think this must be the earliest on record. On February rgth, 1905, a midwife reported that a child had just been born with meconium coming away from the umbilical cord. I found a fistula the size of a crow's quill about $I$ in. from the umbilical aperture in the side of the cord exuding meconium.

The same day, without anaesthetic, I slit the cord longitudinally, exposing a blind finger-like process of intestine with the fistula in its side. On drawing it out of the umbilical aperture it was found to be about 2 in. long and to come from the caecum ; the intestine on either side of it was so narrow that I did not think it capable of maintaining the alimentary passage. I excised the narrowed intestine and joined the large to the small intestine by lateral anastomosis, closing the end of the large intestine. The intestine was returned into the abdomen and the umbilical aperture closed after removal of the umbilieal cord.

The child was very sick for two days, but meconium escaped from the anus and it recovered perfectly.

I have previously reported the radical cure of hernia into the cord in a one day old infant, in the BrITISH Mrdical JOURNAI, and this case seems to have been one of a persistent Meckel's diverticulum, though I am not sure that it was not an enlarged appendix which had perforated. There was no sign of any appendix on the excised caecum.

The only points worthy of note are that a newly-born infant bears the handling of its intestine well and, as far as one can tell, does not feel pain, the infant quietly sucked a sugared teat while its intestine was being stitched.

Plaistow, E.

A. E. K HNNEDY

Honorary:Surgeon, Matornity Charity.
A CASE OF MESOTAN ERUPTION.

Thi following case came recently under my observation, the patient being a lady, aged 39, with a fair complexion and a skin of very fine texture.

History. - She had suffered from a mild attack of rheumatism, which had affected chiefly the feet and ankles, and also the metacarpophalangeal joint of each thumb. She had been treated with salicin, and afterwards with alkalies, with only a moderate degree of benefit, and at length an embrocation, consisting of mesotan and olive oil in equal proportions, was prescribed, with instructions that it should be very gently applied to the feet and ankles. In about ten or twelve days a rash appeared, not only on the parts to which the embrocation had been applied, but also on the arms, and it was on account of this rash that the patient sought advioe.

Appearances Noted.-The parts implicated were the extensor aspects of the arms from a little above the elbow to half way down the forearms, the right arm being more extensively involved than the left, and the outer aspect of the right lower leg. The eruption presented much the same appearances in all the lesions-namely, a pinkish-red colour, somewhat mottled, deepest in tint towards the centre, and fading rapidly at the edges into the colour of the normal skin. It was a simple erythema, without infiltration or vesiculation, and the chief trouble it caused was intense burning and itchiness. She said the embrocation had not really been rubbed in, but only smeared over the ankles, and she was satisfied that it had been of service as far as the rheumatism was concerned, but she considered the resulting burning and pruritus a somewhat heavy penalty to pay for such benefit.

Treatment and Result. - She was advised by me to continue taking the alkalies-citrate and bicarbonate of potassium-to stop the use of the embrocation, and to paint the inflamed parts with a lotion of calamine and oxide of zinc. In the course of a few days the redness disappeared, and in a few days longer the unpleasant sensations had likewise ceased.

REMARKS.-Both in regard to appearance and sensations the case answers to the description of mesotan rash given by Pollitzer of New York in a paper which he read before the American Dermatological Association in 1903.' The paper, which was afterwards published, contains details of two cases of rheumatism, both in elderly men, in whom the use of mesotan brought out eruptions of a much more severe character than that in my patient. In one of them the drug had been applied in full strength, and persevered with even after the rash had disappeared, with the result that vesicles developed which on rupture and drying left crusts. This second case ran much the same course, but, the mesotan having been diluted with olive oil, the dermatitis was not so severe. Both cases were treated successfully with ichthyol, dusting powders, and Lassar's paste, sine salicylic acid, but the patients suffered severely while the condition lasted. It is to be noted that the rheumatism was relieved in both cases. Besides detailing his own cases, Pollitzer in the same paper quotes a few instances of others which had been published.

There can, I think, be little doubt of the value of mesotan in the treatment of rheumatism, but that its use requires caution and careful supervision is clear. I am not sure whether it is much in use in this country or not; so far this is the only case of the kind I have seen, and if others besides those of Politzer's have been published they have escaped my notice.

David Couper, M.D.Glagg., Physician in Charge of the Skin Department, Victoria Infirmary, Glasgow.

PURULENT PERITONITIS AFTER PNEUMONIA. ON January 4th E. L., a child, aged 6, developed lobar pneumonia ; on the eighth day crisis took place. Convalescence was slow, and the child remained in a languid state till January 27 th, when the abdomen became suddenly much distended, and there was distinct evidence of fluid. I tapped at once, and drew off 3 pints of pure pus. On January 3 oth the fluid reaccumulated, and the child was admitted to the Cottage Hospital. There the abdomen was opened by Mr. Crabtree; a further large amount of pus was evacuated, the peritoneal cavity washed out, and the wound allowed to granulate. From the crisis at the date mentioned to the time of operation, more than three weeks later, the temperature never exceeded $100^{\circ}$.

A specimen of the pus was sent to H. S. Willson, M.B., D.P.H., Lecturer on Bacteriology, King's College, London, who reported as follows:

Smear preparations stained with methylene blue showed a few encapsuled diplococei among the pus cells. They stained well by Gram's method. No other organism was seen. A loopful of pus spread on glycerine agar, and incubated at $37^{\circ}$ C. for twenty-four hours, 1 A New Drug Fruption of the Iodoform Type. Journal of Cutaneous
Diseases, October, r9o3. 